mothers have always known instinctivelythat the rigid regimen imposed by many maternity units impedes the successful establishment of breast-feeding.

Thanks to the enlightened attitudes of nursing staff in Sunderland Maternity Hospital five years ago, I was able to breast-feed my first-born on demand (and by demand I mean hourly if necessary for the first few days). The ward routine was not affected and he received no complementary feeds. Far from showing the usual weight loss, he recorded $2722 \mathrm{~g}$ at delivery and $3062 \mathrm{~g}$ four days later.

This contrasted markedly with an unhappy experience during a subsequent confinement in a hospital which insisted on a rigid feed schedule and supplementary bottle feeds, with consequent detrimental effects on both mother and child.

I hope that other hospitals will follow the advice and example of the Birmingham team and can only endorse their conviction that this will indeed allay many of the misgivings of women who are at present pressing for home delivery.

Patricia J Bailey-SMith

Edinburgh

\section{Infant feeding practices: a cause for concern}

SIR,-Dr J H Tripp and others (22 September, p 707) have done a great service in presenting a large number of data, in useful and assimilable form, regarding alternatives to cows' milk when breast-feeding is impossible. They correctly point out that goats' milk and other preparations all present problems; and even Prosobee, to which they give guarded approval, has too much protein and electrolytes. None of these preparations can, of course, protect the infant from infection or allergy (though goats' milk has an anecdotal reputation in this respect).

The only infant food that approaches at all closely the mother's milk is another mother's milk (a fact clearly appreciated by livestock farmers). Breast-milk banks are in use in various centres for special-risk neonates, but the amount collected could never be sufficient to cope with all the normal infants whose mothers cannot or will not breast feed. Over the last three years we have been collecting large volumes of donated breast milk for therapeutic use in older children and adults, with relatively little trouble or expense, and the paper by Dr Tripp and others stimulates us to relate our experience.

Prospective donors are recruited via the National Childbirth Trust, whose local groups act as contact foci for many expectant mothers (admittedly of a rather middle-class character). Pregnant women are issued with a leaflet explaining the uses to which breast milk can be put and inviting them to contact the group leader, after the baby is born, if they wish to donate any excess milk to the trust' milk bank. Milk (or colostrum) is collected into clean plastic bags, which are unused but not therwise sterilised. Mothers may either catch the drops produced by the let-down reflex, express manually, or use a breast pump (the Kaneson is currently recommended as the most comfortable). One session can result in anything from $20 \mathrm{ml}$ to $200 \mathrm{ml}$, which is immediately frozen in its bag, by the donor herself if she has a freezer or by a local group member if not. Each package is labelled with donor's name and date. From time to time all supplies collected by the group are gathered together by one to three freezer-owning members, and a van equipped with dry-ice refrigerator is dispatched to pick them up. Each donor's GP is sent a questionnaire relating to the health of mother and child (including details of drugs, etc) and so far virtually $100 \%$ of the doctors have responded. Shortly before use packages representing 8-12 donors are thawed and tested for hepatitis antigen. Random samples (at least one from each donor) are also plated on to blood and MacConkey agar aerobically. So far no specimen has contained $3 \times 10^{6}$ organisms per litre (our rejection criterion) and none has contained hepatitis antigen or had $\mathrm{pH}<7 \cdot 0$. The packages used for testing (small ones if possible) are then thrown away, and that donor is considered "cleared." The appropriate amount of milk (from cleared donors) is then thawed, pooled, dispensed into new plastic bottles, and refrozen, remaining in that state until use.

In this way we have collected some $30-40$ litres of breast milk a year from one relatively small group of donors. Apart from the hundreds of woman-hours donated gratis by the mothers and National Childbirth Trust organisers, the total cost has not exceeded $£ 200$ per year (that is, $£ 5-7$ per litre). This, of course, is much more expensive than "normal" infant feeds but is not prohibitive. We need not aim to provide the complete nutritional needs of a baby for very long (say one month), and the cost might be weighed against the infectious and allergic illnesses that the babies might otherwise have suffered later. If, as some believe, early bottle-feeding also causes ischaemic heart disease in later life, ${ }^{1}$ the cost of breast milk is not that great after all. The only objectionable aspect of this food is the unpleasant taste and smell imparted by storage in plastic containers.

DAvid Freed

University Department of Bacteriology Manchester M13 9PT

DEIRDRE MACKAY

National Childbirth Trust,

Little Budworth, Cheshire

Austin, C, The Cow and the Coronary. Hicksville USA, Exposition Press, 1979.

\section{Drug names that look or sound alike}

SIR,-I should like to make an important addition to the list of drug names that look or sound alike (6 October, p 836). On inquiring about the progress of a 40-year-old man who had presented with a stroke and malignan hypertension, I was told that he had "just had another dose of isoprenaline." $\mathrm{He}$ had, in fact, been given Apresoline (hydrallazine) as ordered, and the effects on his blood pressure and mine were the exact opposite.

RICHARD A FAIRBURN

London SE9 2SD

SIR,-Mr H McNulty and Mr P Spurr (6 October, p 836) draw attention to drug names that look and sound alike and invite any additions.

A clerical officer aged 55 was seen by another doctor on 2 May 1979 with bilateral otitis externa. Fifteen Remotic (Squibb) capsules were prescribed, to be used thrice daily. The patient was told that the capsules looked like capsules of lighter fuel and that one end was to be cut off and the contents squirted into the ears three times a day.

On 5 May the patient's wife phoned to say angrily that the treatment had "made him bad" and unfit to drive. The chemist had dispensed 15 tablets of Rivotril (Roche, clonazepam) $0.5 \mathrm{mg}$, an orange tablet to be taken three times a day.
That a supposedly intelligent patient, having been told to use capsules of Remotic in the ear, should then eat tablets of Rivotril will surprise no one with 30 years in general practice.

C ROMER

Worcester

\section{Diazepam for distressing procedures}

SIR,-Dr E R Craven (6 October, p 867) rightly emphasises the patient's anxiety when confronted with a sternal puncture needle, and suggests marrow biopsy from the posterior iliac crest. No doubt this is a good idea, but when it comes to needles reassurance is difficult and time consuming. Moreover, some procedures such as lumbar puncture have an evil reputation and it may be impossible to allay anxiety.

Anxiety enhances pain and in my experience it is far easier and more effective to use intravenous diazepam as a premedication for these and other distressing procedures. Provided the dose is carefully titrated and provided the drug is avoided in patients with respiratory failure and obstructive airways disease, intravenous diazepam is extremely safe and allows one to perform a large variety of procedures without distress. The addition of Cyclimorph enables one also to undertake very painful procedures such as reduction of fractures and operations under local anaesthesia with exsanguinating tourniquets.

Resistance to diazepam builds up rapidly and large doses may be required for patients on long-term medication. I would therefore make a plea to restrict the use of diazepam to acute situations, where it is so effective. Continued medication with diazepam produces diminishing returns and long-term effects resemble those from alcohol-namely, depression and irritability. However, it is fortunate that benzodiazepines can be discontinued without serious withdrawal symptoms.

A W FOWLER

Bridgend General Hospital,
Bridgend, Mid Glam CF31 1JP

\section{Personality and breast cancer}

SIR,-_"Medicine and the Media" (20 October, p 996) contains an unjustified complaint that my account in Now! (5 October, p 60) of Dr Stephen Greer's work on personality and breast cancer made no mention of his paper in the Lancet (13 October, p 785) and adds (sarcastically ?) that "perhaps it was just coincidence" that similar findings were reported that same week in the fournal of the American Medical Association (5 October, p 1504).

Well, for a start, it was just coincidence. And I made no mention of the Lancet paper because -if only out of enlightened self-interest-I try to be scrupulous about not breaking publication embargoes. Also, I am certain that $\mathrm{Dr}$ Greer would not have wished to break the embargo on his own paper (and can hardly be well pleased with an insinuation in the $B M F$ that he did so). My article therefore made no use of his paper. In any case, it was based on the actual questionnaire used in the Royal Marsden's trials rather than the paper about it, and my report depended chiefly on my own interview with Dr Greer. He did not even refer to his paper in our conversation and I was 